\title{
Functional alpha-1B adrenergic receptors on human epicardial coronary artery endothelial cells
}

\author{
Brian C. Jensen • Philip M. Swigart • \\ Megan D. Montgomery • Paul C. Simpson
}

Received: 29 July 2010 /Accepted: 30 August 2010 / Published online: 22 September 2010

(C) The Author(s) 2010. This article is published with open access at Springerlink.com

\begin{abstract}
Alpha-1-adrenergic receptors ( $\alpha 1$-ARs) regulate coronary arterial blood flow by binding catecholamines, norepinephrine (NE), and epinephrine (EPI), causing vasoconstriction when the endothelium is disrupted. Among the three $\alpha 1$-AR subtypes $(\alpha 1 \mathrm{~A}, \alpha 1 \mathrm{~B}$, and $\alpha 1 \mathrm{D})$, the $\alpha 1 \mathrm{D}$ subtype predominates in human epicardial coronary arteries and is functional in human coronary smooth muscle cells (SMCs). However, the presence or function of $\alpha 1$-ARs on human coronary endothelial cells (ECs) is unknown. Here we tested the hypothesis that human epicardial coronary ECs express functional $\alpha 1$-ARs. Cultured human epicardial coronary artery ECs were studied using quantitative real-time reverse transcription polymerase chain reaction, radioligand binding, immuno-
\end{abstract}

B. C. Jensen · P. M. Swigart

Cardiology Division, VA Medical Center;

and Department of Medicine,

University of California, San Francisco,

San Francisco, CA, USA

M. D. Montgomery • P. C. Simpson

Cardiology Division, VA Medical Center; and Cardiovascular

Research Institute and Department of Medicine,

University of California, San Francisco,

San Francisco, CA, USA

P. C. Simpson $(\square)$

VA Medical Center (111-C-8),

4150 Clement St.,

San Francisco, CA 94121, USA

e-mail: paul.simpson@ucsf.edu

Present Address:

B. C. Jensen

Cardiology Division, University of North Carolina,

160 Dental Circle,

Chapel Hill, NC 27599-7075, USA blot, and ${ }^{3} \mathrm{H}$-thymidine incorporation. The $\alpha 1 \mathrm{~B}$-subtype messenger ribonucleic acid (mRNA) was predominant in cultured human epicardial coronary ECs $(90-95 \%$ of total $\alpha 1$-AR mRNA), and total $\alpha 1$-AR binding density in ECs was twice that in coronary SMCs. Functionally, NE and EPI through the $\alpha 1 \mathrm{~B}$ subtype activated extracellular signalregulated kinase (ERK) in ECs, stimulated phosphorylation of EC endothelial nitric oxide synthase (eNOS), and increased deoxyribonucleic acid (DNA) synthesis. These results are the first to demonstrate $\alpha 1$-ARs on human coronary ECs and indicate that the $\alpha 1 \mathrm{~B}$ subtype is predominant. Our findings provide another potential mechanism for adverse cardiac effects of drug antagonists that nonselectively inhibit all three $\alpha 1-\mathrm{AR}$ subtypes.

Keywords Human heart · Endothelial cell · Coronary artery $\cdot$ Alpha-1-adrenergic receptor · Alpha-adrenergic antagonists

\section{Introduction}

Alpha-1-adrenergic receptors ( $\alpha 1$-ARs) regulate coronary artery blood flow in response to the catecholamines norepinephrine (NE) and epinephrine (EPI). $\alpha 1$-ARs on vascular smooth muscle cells (SMCs) mediate contraction. Interestingly, however, $\alpha 1$-AR stimulation causes minimal constriction of normal coronary arteries, but markedly constricts coronary arteries with disrupted endothelium (Baumgart et al. 1999; Heusch et al. 2000). A likely mechanism is loss of endothelial nitric oxide synthase (eNOS) activation and vasodilator NO when endothelial cells (ECs) are lost (Zembowicz et al. 1991; Jones et al. 1993). However, nothing is known about $\alpha 1$-ARs on human coronary endothelial cells (ECs). 
$\alpha 1$-ARs exist as three molecular subtypes, $\alpha 1 \mathrm{~A}, \alpha 1 \mathrm{~B}$, and $\alpha 1 D$. All three subtypes are activated by NE and EPI, but differ in amino acid sequence, tissue expression, and signaling (Graham et al. 1996). Little is known about $\alpha 1$-AR subtypes in ECs of any vascular bed or species. A few earlier studies suggested that the $\alpha 1 \mathrm{D}$ subtype was present in ECs from different vascular beds in animals (Filippi et al. 2001; de Andrade et al. 2006; Mendez et al. 2006) and in human umbilical vein ECs (Vinci et al. 2007). However, $\alpha 1$-ARs in epicardial coronary artery ECs have never been studied, in animals or humans.

Recently, we showed that the $\alpha 1 \mathrm{D}$ is the predominant $\alpha 1$ AR subtype in human epicardial coronary arteries, which have low levels of the $\alpha 1 \mathrm{~B}$ subtype ( $25 \%$ or less of total $\alpha 1$-ARs) and little or no $\alpha 1 \mathrm{~A}$ (Jensen et al. 2009b). The $\alpha 1 \mathrm{D}$ subtype is also expressed and functional on human coronary SMCs (Jensen et al. 2009b) and causes constriction of mouse coronary arteries (Turnbull et al. 2003; Chalothorn et al. 2003). In striking contrast with coronary arteries, the human and mouse myocardium and cardiac myocytes express nearequal levels of the $\alpha 1 \mathrm{~A}$ and $\alpha 1 \mathrm{~B}$ subtypes, with little or no $\alpha 1 \mathrm{D}$ (Jensen et al. 2009a; O'Connell et al. 2003).

Which $\alpha 1$-subtypes are present on human coronary ECs is potentially very important clinically. Subtype-nonselective $\alpha 1$-adrenergic antagonists, such as doxazosin and prazosin, are in widespread clinical use, especially to treat prostate disease in men and hypertension. However, large clinical trials detected adverse cardiac effects of nonselective $\alpha 1$-antagonists (ALLHAT CRG 2000; Cohn 1993). We suggested recently that adaptive signaling through the $\alpha 1 \mathrm{~A}$ and $\alpha 1 \mathrm{~B}$ subtypes in myocardium and myocytes might explain these adverse effects in part (Jensen et al. 2009a; O'Connell et al. 2006). Furthermore, inhibiting an $\alpha 1$-AR subtype in epicardial coronary ECs might disturb endothelial-dependent vasodilation. Thus, the presence of $\alpha 1$-ARs on epicardial coronary ECs would suggest another possible explanation for cardiac side effects of nonselective alpha-blockers. Here, we tested the hypothesis that human epicardial coronary ECs express functional $\alpha 1$-ARs.

\section{Materials and methods}

Human epicardial coronary artery EC culture

Clonetics normal human coronary artery ECs were from Lonza (Walkersville, MD, \#CC2585, Lots 7F3649, 7F3667, and 7F4280). All cells were cultured in Clonetics EGM-2 medium [including human recombinant epidermal growth factor, fibroblast growth factor, insulin-like growth factor-1, vascular endothelial growth factor, heparin, and $2 \%$ fetal bovine serum (FBS)] and were used between passages 3 and 10 , at $80-100 \%$ confluence.
Primary human coronary artery EC cultures came from heart transplants at the University of California, San Francisco (UCSF), with the approval of the UCSF Committee for Human Research and with full informed consent. The heart was perfused with cold cardioplegia in situ and explanted immediately into ice-cold physiologic solution. Epicardial coronary arteries were dissected, cleaned rapidly of fat, transported in ice-cold physiologic solution, then opened longitudinally and digested $20 \mathrm{~min}$ in Hanks buffer with collagenase type II (1 mg/ml, Worthington). The endothelium was removed with gentle scraping; the vessel was washed three times; collagenase was inactivated by EGM-2; and the cellular fraction was centrifuged at 1,200 rpm for $5 \mathrm{~min}$. Cells were plated and grown in EGM-2 as with Lonza ECs and assayed at $\sim 80 \%$ confluence.

Human coronary artery SMC culture

Clonetics normal human coronary artery SMCs from Lonza (\#CC2583) were cultured in Dulbecco's modified Eagle's medium (DMEM) with 10\% FBS for 3-11 passages and harvested at $\sim 70 \%$ confluence.

Quantitative real-time reverse transcription (RT) PCR (qPCR)

Cultured coronary artery ECs from one T75 flask were washed with phosphate buffered saline (PBS), and ribonucleic acid (RNA) was extracted, purified (Qiagen RNeasy Mini Kit), and treated with DNase (Turbo DNAfree, Ambion). The approach was validated previously (Jensen et al. 2009a).

RT reactions used $1 \mu \mathrm{g}$ RNA, SuperScript III Reverse Transcriptase (Invitrogen), random hexamers (Invitrogen), and oligo-dT (Roche). qPCR was done in triplicate in an ABI PRISM 7900HT Sequence Detection System (SDS) with $5 \%$ of the RT product, primers at $125 \mathrm{nM}$, and SYBR Green Master (Roche) with ROX reference dye. Data were analyzed with SDS software version 2.3 (Applied Biosystems).

Primers were:

- $\beta$-actin forward (F) ATTGGCAATGAGCGGTTC, $\beta$ actin reverse (R) GGATGCCACAGGACTCCAT;

- TATA-binding protein (TBP) F GGGCACCACTC CACTGTATC, TBP R CTCATGATTACCGCAG CAAA;

- $\alpha 1 \mathrm{~A}$ F GGCTCCTTCTACCTGCCTCT, $\alpha 1 \mathrm{~A}$ R AGGGCTTGAAATCAGGGAAG;

- $\alpha 1 \mathrm{~B}$ F CCTGAGGATCCATTCCAAGA, $\alpha 1 \mathrm{~B}$ R GGTTGAGGCAGCTGTTGAAG;

- $\alpha 1 \mathrm{D}$ F TCTGCTGGTTCCCTTTCTTC, $\alpha 1 \mathrm{D}$ R CACGCAGCTGTTGAAGTAGC; 
- 33 -AR F ATGCCAATTCTGCCTTCAAC, $\beta 3-A R$ R CTTGGGGAGTTTCTTAGGCC;

- Smooth muscle myosin heavy chain (sm-MHC) F GGAGGCCCTAAAGACAGAGC, sm-MHC R TCTTCAGCACCGTCACCTC; and

- Platelet/endothelial cell adhesion molecule-1 (PECAM1) F AgGtTCtgaggGtgaAgGtG, PECAM-1 R ACAGCACATTGCAGCACAA

Relative quantitation of PCR products used the $\Delta \Delta \mathrm{CT}$ method, with normalization to two reference genes for improved accuracy, where arbitrary units (AU) were $2^{-\Delta \Delta \mathrm{CT}} \times 1,000(\mathrm{CT}=$ cycles to threshold, and $\Delta \Delta \mathrm{CT}=$ [(mean target gene CT)-(mean CT of $\beta$-actin+TBP)].

Radioligand binding

ECs or SMCs $(12 \times 100 \mathrm{~mm}$ dishes or $16 \times \mathrm{T} 75$ flasks $)$ were rinsed, scraped directly into binding buffer $(5 \mathrm{mM}$ Tris- $\mathrm{HCl}$, $\mathrm{pH} 7.4,5 \mathrm{mM}$ EDTA), and sonicated. $\alpha 1$-AR saturation binding used $85-95 \mu \mathrm{g}$ cell protein in $1 \mathrm{ml} /$ tube with six concentrations $(0.04-1.2 \mathrm{nM})$ in triplicate of ${ }^{3} \mathrm{H}$-prazosin (Perkin-Elmer); phentolamine (10 $\mu \mathrm{M}$, Sigma \#P7561) defined nonspecific binding. All incubations were $60 \mathrm{~min}$ at $30^{\circ} \mathrm{C}$. Prism 4.0a (GraphPad Software, San Diego, CA) analyzed binding data.

Pharmacology and immunoblots

For experiments, EC cultures in $35 \mathrm{~mm}$ culture dishes (Falcon) were serum-starved for $2 \mathrm{~h}$ in DMEM with $5 \mathrm{mg} / \mathrm{ml}$ bovine serum albumin (BSA), then were pre-incubated for 15 min without or with $\alpha 1$-AR-antagonists including BMY-7378 (8-[2-[4-(methoxyphenyl)-1-piperazinyl]ethyl]8-azaspiro[4.5]decane-7,9-dione dihydrochloride, Sigma \#B134) or prazosin (Sigma \#P7791). The nonselective $\beta$ AR antagonist L-propranolol (Sigma \#P8688) was also present throughout. Agonists or vehicle $(100 \mu \mathrm{M}$ ascorbic acid) were then added including L-NE-bitartrate (Sigma \#N5785), L-EPI-bitartrate (Sigma \#E4375), A61603 (N[5-(4,5-dihydro-1 $H$-imidazol-2-yl)-2-hydroxy-5,6,7, 8-tetrahydronaphthalen-1-yl]methanesulfonamide hydrobromide, Tocris \#1052, Ellisville, MO), or UK-14,304 [5-bromo- $N$ - (2-imidazolin-2-yl)-6-quinoxalinamine, 5bromo- $N$-(4,5-dihydro- $1 H$-imidazol-2-yl)-6-quinoxalinamine, Sigma \#U104].

After agonist treatment, homogenates were made in radioimmunoprecipitation assay (RIPA) buffer with protease and phosphatase inhibitors. Total cell lysates were used in immunoblots with antibodies for total-ERK1/2 (Cell Signaling rabbit pAb \#9102), phospho-ERK1/2 (Cell Signaling rabbit mAb Thr202/Tyr204 \#4370), total-eNOS (BD Transduction Laboratories \#610296), and phospho-
eNOS (Cell Signaling Ser-1177 \#9571; BD Transduction Ser-633 \#612665). Signals from enhanced chemiluminescence detection were quantified with a Bio-Rad ChemiDoc Molecular Imager (Hercules, CA).

Antibodies for cell phenotyping were PECAM-1 (R\&D Systems \#BBA7), smooth muscle actin (Zymed \#08-0106), and sm-MHC (Biomedical Technologies \#BT-562, Stoughton, MA).

${ }^{3} \mathrm{H}$-Thymidine incorporation

DNA synthesis was estimated by measuring incorporation of ${ }^{3} \mathrm{H}$-thymidine. ECs at $80-90 \%$ confluence in 24 -well plates in EGM-2 were serum-starved and pre-incubated for $4 \mathrm{~h}$ in DMEM with BSA ( $5 \mathrm{mg} / \mathrm{ml}$, Sigma \#A7030) and L-propranolol $1 \mu \mathrm{M}$, without or with prazosin $0.2 \mu \mathrm{M}$. Cells were then incubated in the same medium with ${ }^{3} \mathrm{H}-$ thymidine, without or with NE or EPI. After $24 \mathrm{~h}$, cells were extracted with $10 \%$ trichloroacetic acid for $12 \mathrm{~h}$, washed, dissolved in $1 \%$ SDS for $1 \mathrm{~h}$, and counted in minivials with $5 \mathrm{ml}$ Opti-fluor (Perkin-Elmer).

Data analysis

Results are mean \pm SEM. Significant differences $(p<0.05)$ were tested using Student's unpaired $t$-test for two groups, and analysis of variance (ANOVA) and Tukey's multiple comparison for more than two groups. Concentrationresponse curves were fit with Prism 4.0a.

\section{Results}

Validation of human epicardial coronary EC cultures

Human coronary ECs from Lonza were from two females (ages 56 and 57) and one male (age 21). These ECs all expressed high levels of PECAM-1 mRNA and no smMHC, as expected (data not shown). Our primary cultures of human epicardial coronary ECs were from one male without coronary artery disease (age 46) and were validated by positive immunoblot for PECAM-1 and by negative immunoblot for smooth muscle actin and sm-MHC (data not shown).

$\alpha 1 \mathrm{~B}-\mathrm{AR}$ subtype mRNA predominates in human coronary ECs (Fig. 1)

We quantified $\alpha 1$-AR subtype mRNAs using qPCR with primers validated previously that span the single intron in each $\alpha 1$-AR subtype gene to eliminate artifacts from genomic DNA contamination (Jensen et al. 2009a). In the Lonza ECs, $92 \%$ of total $\alpha 1$-AR mRNA 
a Quantitative real-time reverse transcription PCR $(\mathrm{N}=4)$

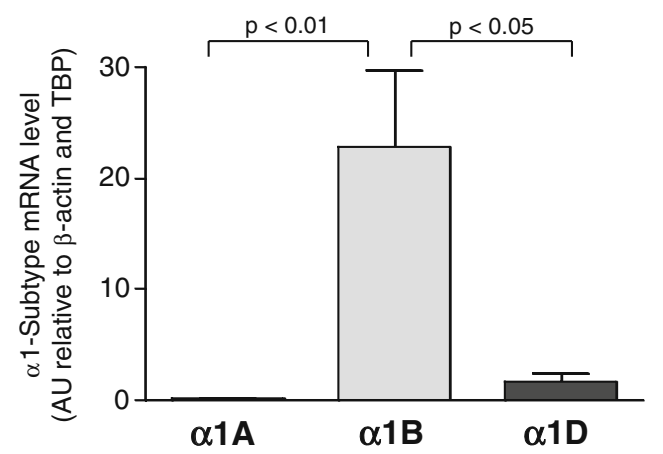

\section{b Saturation radioligand binding}



Fig. $1 \propto 1$-ARs in human epicardial coronary ECs. $\alpha 1$-AR subtype mRNAs were quantified by qPCR in Lonza cultured ECs $(N=4$, a), and total $\alpha 1$-ARs were measured by saturation radioligand binding (b)

was $\alpha 1 \mathrm{~B}$, with the remainder small amounts of $\alpha 1 \mathrm{D}$, and little or no $\alpha 1 \mathrm{~A}(N=4$ independent cultures from three subjects, Fig. 1a). There was no detectable $\beta 3$-AR mRNA (data not shown). In our primary human epicardial ECs, $90 \%$ of total $\alpha 1$-AR mRNA was $\alpha 1 \mathrm{~B}$ ( $N=2$ cultures from one subject).

\section{$\alpha 1$-AR binding is higher in ECs than in SMCs (Fig. 1)}

To test $\alpha 1$-AR protein levels, we used saturation radioligand binding with ${ }^{3} \mathrm{H}$-prazosin. We could not use immunohistochemistry or immunoblot, because there are no antibodies specific for $\alpha 1$-ARs, among 10 antibodies that we tested (Jensen et al. 2009c), or three antibodies tested by others (Pradidarcheep et al. 2009).

Saturation binding identified $34 \mathrm{fmol} / \mathrm{mg}$ protein of total $\alpha 1$-ARs in coronary ECs, with a $\mathrm{Kd} 0.07 \mathrm{nM}$, and specific binding $90 \%$ of total at the ${ }^{3} \mathrm{H}$-prazosin Kd (Fig. 1b). For comparison, in parallel experiments, we found that Lonza human coronary SMCs contained $17 \mathrm{fmol} / \mathrm{mg}$ protein of total $\alpha 1$-ARs. We did not perform competition radioligand binding on ECs given the marked predominance of $\alpha 1 \mathrm{~B}$ mRNA in our qPCR assays. $\alpha 1 \mathrm{~B}$ subtype activates ERK in coronary artery ECs (Fig. 2)

To test for functional $\alpha 1$-ARs in human coronary ECs and to determine the $\alpha 1$-AR subtype at the protein level, we used immunoblot to quantify dual Thr202/Tyr204 phosphorylation (activation) of ERK. ERK is a key target for $\alpha 1$-ARs in cardiac myocytes (Huang et al. 2007) and is a key element of important signaling pathways in ECs that promote angiogenesis (Chung et al. 2008), and EC migration, survival, and proliferation (Lian et al. 2001;

a Agonist doses at 15 min stimulation

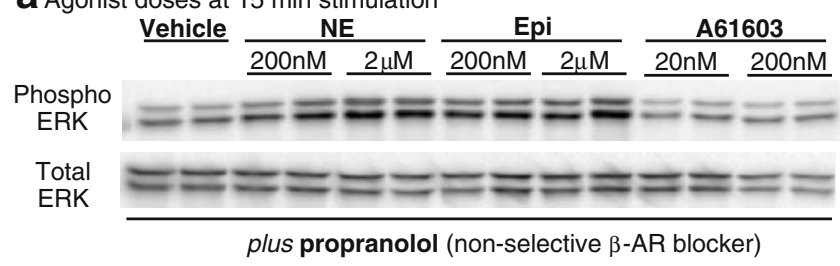

b summary of NE-mediated ERK activation (all with propranolol)

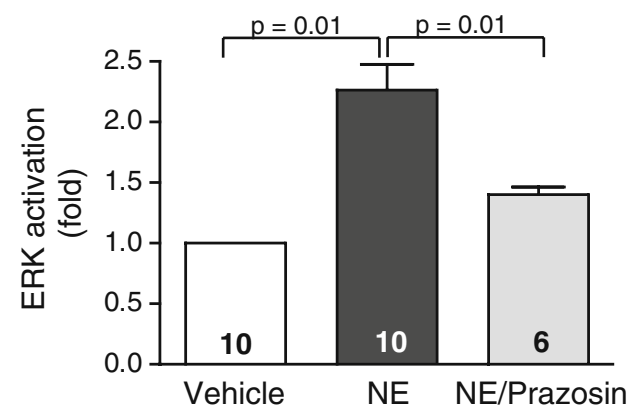

C BMY-7378 ( $\alpha$ 1D-selective) inhibition of NE-mediated ERK activation

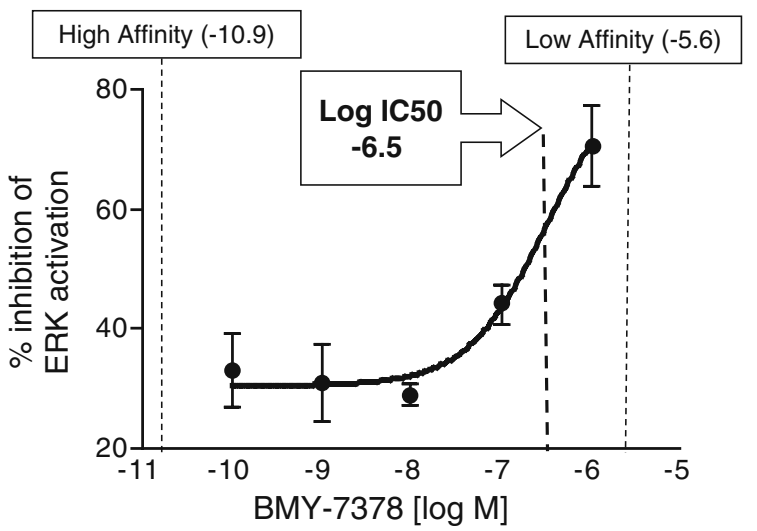

Fig. 2 The $\alpha 1 B-A R$ subtype activates ERK in coronary ECs. Cultured ECs were treated for $15 \mathrm{~min}$ with the drugs indicated, and total and phosphorylated ERK were quantified by immunoblot. The nonselective $\beta$-AR antagonist propranolol $(1 \mu \mathrm{M})$ was present throughout in all groups. a Representative blot with NE, EPI, and the $\alpha 1$ A-selective agonist A61603. b ERK activation by NE (mean $1 \mu \mathrm{M}$, range $0.2-2 \mu \mathrm{M}$ ) is inhibited by the nonselective $\alpha 1$-antagonist prazosin $(1 \mu \mathrm{M}, N=6-10)$. c The $\alpha 1 \mathrm{D}$-selective antagonist, BMY7378, inhibited NE $(1 \mu \mathrm{M})$-stimulated phospho-ERK with a log IC50 of $-6.5(N=5)$. This value is much closer to the known low-affinity BMY-7378 site (log IC50 -5.6) than the high-affinity site (-10.9) 
Mavria et al. 2006; Nakagami et al. 2001; Secchiero et al. 2003).

Human coronary ECs from Lonza were treated $15 \mathrm{~min}$ with the non-subtype-selective natural $\alpha 1$-AR agonists NE and EPI, and the $\alpha 1 \mathrm{~A}$-selective agonist, A61603, in the presence of propranolol, a $\beta$-AR antagonist. NE increased phospho-ERK by 2.2 -fold, and the general $\alpha 1$-AR antagonist prazosin reduced this activation by $70 \%(p=0.01, N=$ 6-10 cultures; Fig. 2a-b). The $\alpha 1 \mathrm{~A}$ agonist A61603 did not activate ERK ( $N=3$; Fig. 2a). The subtype-nonselective $\alpha 2$ AR agonist UK-14,304 $(10 \mu \mathrm{M})$ increased phospho-ERK by only 1.11 -fold.

These data indicated that an $\alpha 1$-AR subtype activated ERK in human coronary ECs and that the subtype was not the $\alpha 1 \mathrm{~A}$, because A61603 was inactive. To determine whether the $\alpha 1 \mathrm{~B}$ and/or $\alpha 1 \mathrm{D}$ activated ERK, we used an $\alpha 1 \mathrm{D}$-selective agent, because there are no reliable $\alpha 1 \mathrm{~B}$ selective agonists or antagonists. We quantified ERK phosphorylation after stimulation with $\mathrm{NE}(1 \mu \mathrm{M})$ for $15 \mathrm{~min}$, in the presence of propranolol to block $\beta$-ARs, and varying concentrations of BMY-7378 $(1 \mathrm{nM}-1 \mu \mathrm{M})$, the $\alpha 1 \mathrm{D}$-selective antagonist.

Previously, we found that BMY-7378 competed for ${ }^{3} \mathrm{H}-$ prazosin binding to human epicardial coronary artery $\alpha$-ARs at two receptor sites, one with high affinity ( $\log$ IC50 -10.9, the $\alpha 1 \mathrm{D}$ ) and the other with low affinity (log IC50 -5.6, the $\alpha 1 \mathrm{~A}$ or $\alpha 1 \mathrm{~B}$; Jensen et al. 2009b). In the present experiments, BMY-7378 inhibited NE-stimulated phospho-ERK with a log IC50 -6.5 , very close to the low affinity $\log \operatorname{IC} 50 \quad(N=5$ cultures; Fig. 2c). These data showed that NE-induced ERK phosphorylation in human coronary ECs is not mediated by the $\alpha 1 \mathrm{D}$, because BMY-7378 inhibited with low affinity, and therefore is mediated by the $\alpha 1 \mathrm{~B}$.

In summary, human coronary artery ECs expressed functional $\alpha 1 \mathrm{~B}-\mathrm{ARs}$ that activated the important intracellular mediator ERK in response to stimulation by modest concentrations of adrenergic agonists.

\section{$\alpha 1$-ARs activate eNOS in ECs (Fig. 3)}

eNOS is a key regulator of EC function, including vasorelaxation and angiogenesis (Zembowicz et al. 1991; Murohara et al. 1998), and is activated by $\alpha 1$-ARs in some systems (Hodges et al. 2005). To test whether $\alpha 1$-ARs in human epicardial coronary ECs signal through eNOS, we treated with $\alpha 1-\mathrm{AR}$ agonists and measured increased phosphorylation of eNOS at two common activation sites (Ser-1177 and Ser-633).

NE $(1 \mu \mathrm{M})$ and EPI $(2 \mu \mathrm{M})$ in the presence of propranolol each transiently increased phosphorylation of eNOS at Ser-1177, with a maximum at $30 \mathrm{~min}$ (Fig. 3a). In three independent cultures, $\alpha 1-\mathrm{AR}$ stimulation increased phopsho-eNOS (Ser-1177) by 1.85 -fold over a Time course of eNOS phosphorylation

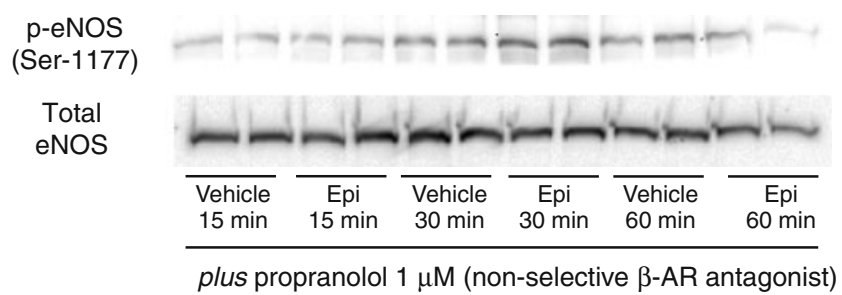

b Summary of EPI -mediated eNOS activation at $30 \mathrm{~min}$

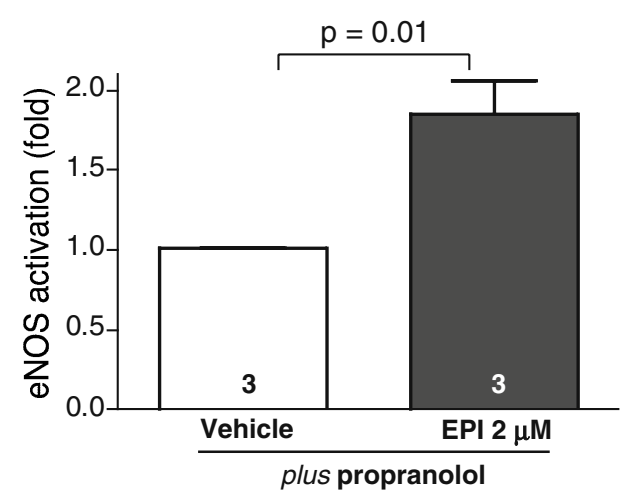

Fig. $3 \propto 1-A R$ stimulation activates eNOS in coronary ECs. Cultured ECs were treated for 15-60 min (a) with EPI $(2 \mu \mathrm{M})$ in the presence of propranolol $(1 \mu \mathrm{M})$, and phosphorylation of eNOS Ser-1177 was assayed by immunoblot. Maximum activation was at $30 \min (N=3, \mathbf{b})$

vehicle $(p=0.01)$ but did not change phosphorylation at Ser-633. The $\alpha 1 \mathrm{~A}$-selective agonist, A61603, did not increase eNOS phosphorylation at either Ser-1177 or Ser633 (data not shown).

These data indicated that an $\alpha 1-\mathrm{AR}$, most likely the $\alpha 1 \mathrm{~B}$, activated eNOS at Ser-1177 in human coronary artery ECs. However, we were unable to detect NO production in our cultures using the fluorophore DAF-2 or the Griess reagent.

$\alpha 1$-ARs increase DNA synthesis in human coronary artery ECs (Fig. 4)

Increased DNA synthesis in ECs is a marker for cellular proliferation and angiogenesis. To test whether stimulation of $\alpha 1$-ARs on human coronary ECs increases DNA synthesis, we measured ${ }^{3} \mathrm{H}$-thymidine incorporation after treatment with varying concentrations of $\mathrm{NE}(1 \mathrm{nM}-$ $20 \mu \mathrm{M})$ in the presence of propranolol. NE increased ${ }^{3} \mathrm{H}-$ thymidine incorporation by a modest but significant extent (maximum 1.3 -fold, $p=0.04$ by ANOVA, $N=3-5$ ), with a low EC50 (39 nM) (Fig. 4). Prazosin $(0.2 \mu \mathrm{M})$ eliminated stimulation by NE (data not shown), indicating that the effect was mediated by $\alpha 1$-ARs. By comparison, $5 \%$ FBS increased ${ }^{3} \mathrm{H}$-thymidine incorporation by 2.6 -fold. 


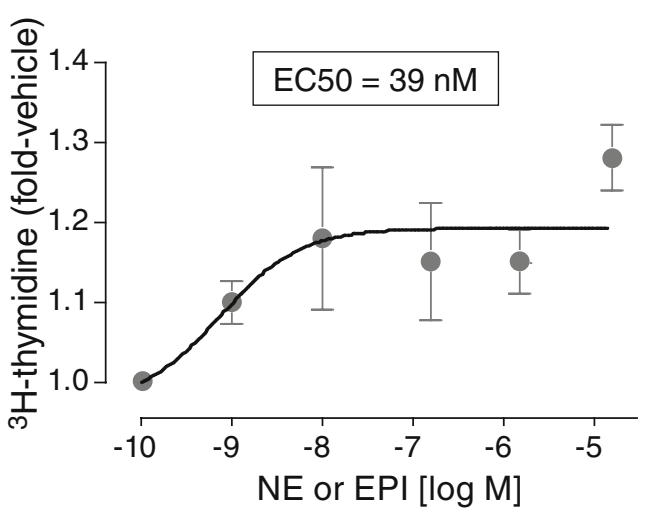

Fig. $4 \alpha 1$-AR stimulation increases DNA synthesis in coronary ECs. EC cultures were treated for $24 \mathrm{~h}$ with NE or EPI $(1 \mathrm{nM}-20 \mu \mathrm{M})$ in the presence of propranolol, and DNA synthesis was estimated by ${ }^{3} \mathrm{H}-$ thymidine incorporation

\section{Discussion}

This study provides the first characterization of $\alpha 1$-ARs in human epicardial coronary ECs and identifies the $\alpha 1 \mathrm{~B}$ as the predominant and functional $\alpha 1-\mathrm{AR}$ subtype. The $\alpha 1 \mathrm{~B}$ subtype is present at relatively high density, and stimulation of the $\alpha 1 \mathrm{~B}$ with modest doses of agonist activates ERK and eNOS and increases DNA synthesis. These results raise the possibility that the $\alpha 1 \mathrm{~B}-\mathrm{AR}$ subtype might have a role in the important adaptive processes mediated by coronary ECs.

We used qPCR and pharmacology to identify the $\alpha 1 \mathrm{~B}$ as the predominant and functional $\alpha 1$-subtype, because $\alpha 1$-AR antibodies are not specific for $\alpha 1$-ARs or $\alpha 1$-subtypes (Jensen et al. 2009c; Pradidarcheep et al. 2009). By qPCR with validated primers, human coronary ECs expressed $>90 \%$ $\alpha 1 \mathrm{~B}$ mRNA, with very little $\alpha 1 \mathrm{D}$, and no detectable $\alpha 1 \mathrm{~A}$. In functional experiments, NE and EPI stimulated phosphorylation of ERK-Thr202/Tyr204 and eNOS-Ser-1177, and the nonselective $\alpha 1$-antagonist prazosin blocked stimulation by $70 \%$. The potent and selective $\alpha 1 \mathrm{~A}$ agonist A61603 did not activate ERK, and the general $\alpha 2$-agonist UK-14,304 had a minor effect. To distinguish the $\alpha 1 \mathrm{~B}$ from the $\alpha 1 \mathrm{D}$, we used the $\alpha 1 \mathrm{D}$-selective antagonist, BMY-7378, because there are no drugs sufficiently selective for the $\alpha 1 \mathrm{~B}$. BMY-7378 inhibited $\alpha 1$-stimulated ERK phosphorylation with low affinity, not the high-affinity characteristic of the $\alpha 1 \mathrm{D}$. Thus, these data identified the $\alpha 1 \mathrm{~B}$-subtype as functional in human epicardial coronary ECs.

The high level of the $\alpha 1 \mathrm{~B}$ in ECs points to an important difference in $\alpha 1$-subtypes in human coronary ECs and SMCs. Recently, we used mRNA and functional assays to show that the $\alpha 1 \mathrm{D}$ subtype is predominant and functional in human coronary SMCs (Jensen et al. 2009b). The $\alpha 1 \mathrm{D}$ is also predominant when assayed by $\mathrm{qPCR}$ and radioligand binding in intact human epicardial coronary arteries (Jensen et al. 2009b). However, when binding was done on isolated cells, as in the present study, the density of the $\alpha 1 \mathrm{~B}$ in ECs was twice that of the $\alpha 1 \mathrm{D}$ in SMCs (34 vs. $17 \mathrm{fmol} / \mathrm{mg}$ ). Thus, the much larger total mass of SMCs likely explains the $\alpha 1 \mathrm{D}$ predominance in intact coronaries, rather than a higher density of $\alpha 1$-ARs on SMCs than on ECs. In fact, it is notable that a minor population of the $\alpha 1 \mathrm{~B}$ is detectable in intact human epicardial coronaries (less than 25\%; Jensen et al. 2009b).

As noted in the "Introduction," $\alpha 1$-stimulation causes minimal constriction of normal coronary arteries but leads to markedly augmented vasoconstriction in coronary arteries with disrupted endothelium. The $\alpha 1 \mathrm{D}$ is predominant in coronary SMCs (Jensen et al. 2009b); the $\alpha 1 \mathrm{D}$ can cause coronary constriction in the $\alpha 1 \mathrm{~A}$ and $\alpha 1 \mathrm{~B}$ double knockout mouse; and coronary constriction is blunted in the single $\alpha 1 \mathrm{D}$ knockout mouse (Chalothorn et al. 2003; Turnbull et al. 2003). Therefore, it is interesting to speculate whether loss of the coronary EC $\alpha 1 \mathrm{~B}$ might be responsible for $\alpha 1$-mediated constriction through the $\alpha 1 \mathrm{D}$ when the endothelium is disrupted, as in atherosclerosis. The coronary EC $\alpha 1 \mathrm{~B}$ might mediate counter-regulatory vasodilation by stimulating eNOS, as shown here. The $\alpha 1 \mathrm{~B}$ might also have a role in EC proliferation and angiogenesis, given the stimulation of ${ }^{3} \mathrm{H}$-thymidine uptake found here. More sophisticated studies in knockout mice will be needed to test these hypotheses, because the $\alpha 1 \mathrm{~B}$ and $\alpha 1 \mathrm{D}$ are very difficult to distinguish by pharmacology, especially in intact animals.

In summary, our present and past results indicate that the $\alpha 1$-AR subtypes are expressed heterogeneously in the human heart. The $\alpha 1 \mathrm{~B}$ is in human epicardial coronary ECs; the $\alpha 1 \mathrm{D}$ is in human epicardial coronary SMCs (Jensen et al. 2009b); and the $\alpha 1 \mathrm{~A}$ and $\alpha 1 \mathrm{~B}$ are in human myocardium (Jensen et al. 2009a). Drugs used for prostate disease and hypertension that block all $\alpha 1$-subtypes nonselectively have adverse cardiac effects in human clinical trials (Cohn 1993; ALLHAT CRG 2000; ALLHAT 2003), and mouse knockouts show that loss of cardiac $\alpha 1 \mathrm{~A}$ and $\alpha 1 \mathrm{~B}$ signaling could account for these adverse effects (O'Connell et al. 2003, 2006). The $\alpha 1 \mathrm{~A}$ subtype has a protective role in cardiac myocytes (Huang et al. 2007; Chan et al. 2008), and the $\alpha 1 \mathrm{~B}$ in epicardial coronary ECs might also have an adaptive role. Potential risks of blocking the $\alpha 1 \mathrm{~A}$ and $\alpha 1 \mathrm{~B}$ might be avoided with $\alpha 1 \mathrm{D}$-selective drugs, such as naftopidil, to relax both prostate and coronary smooth muscle (Takei et al. 1999; Nishino et al. 2006; Kojima et al. 2009).

Acknowledgments PCS was supported by the Department of Veterans Affairs, and the National Heart Lung and Blood Institute at the National Institutes of Health, USA. BCJ was supported by the GlaxoSmithKline Research and Education Foundation for Cardiovascular Disease Award to Young Investigators, and the University of California, San Francisco, Foundation for Cardiac Research. 
Open Access This article is distributed under the terms of the Creative Commons Attribution Noncommercial License which permits any noncommercial use, distribution, and reproduction in any medium, provided the original author(s) and source are credited.

\section{References}

ALLHAT (2003) Diuretic versus alpha-blocker as first-step antihypertensive therapy: final results from the antihypertensive and lipid-lowering treatment to prevent heart attack trial (ALLHAT). Hypertension 42:239-246

ALLHAT CRG (2000) Major cardiovascular events in hypertensive patients randomized to doxazosin vs chlorthalidone: the antihypertensive and lipid-lowering treatment to prevent heart attack trial (ALLHAT). [see comments]. JAMA 283:1967-1975

Baumgart D, Haude M, Gorge G, Liu F, Ge J, Grosse-Eggebrecht C, Erbel R, Heusch G (1999) Augmented alpha-adrenergic constriction of atherosclerotic human coronary arteries. Circulation 99:2090-2097

Chalothorn D, McCune DF, Edelmann SE, Tobita K, Keller BB, Lasley RD, Perez DM, Tanoue A, Tsujimoto G, Post GR, Piascik MT (2003) Differential cardiovascular regulatory activities of the alpha 1b- and alpha 1d-adrenoceptor subtypes. J Pharmacol Exp Ther 305:1045-1053

Chan T, Dash R, Simpson PC (2008) An alpha-1a-adrenergic receptor subtype agonist prevents cardiomyopathy without increasing blood pressure (abstract). Circulation 118:S533

Chung BH, Kim JD, Kim CK, Kim JH, Won MH, Lee HS, Dong MS, Ha KS, Kwon YG, Kim YM (2008) Icariin stimulates angiogenesis by activating the mek/erk- and pi3k/akt/enos-dependent signal pathways in human endothelial cells. Biochem Biophys Res Commun 376:404-408

Cohn JN (1993) The vasodilator-heart failure trials (V-HeFT). Mechanistic data from the va cooperative studies. Introduction. Circulation 87:VI1-VI4

de Andrade CR, Fukada SY, Olivon VC, de Godoy MA, Haddad R, Eberlin MN, Cunha FQ, de Souza HP, Laurindo FR, de Oliveira AM (2006) Alphald-adrenoceptor-induced relaxation on rat carotid artery is impaired during the endothelial dysfunction evoked in the early stages of hyperhomocysteinemia. Eur J Pharmacol 543:83-91

Filippi S, Parenti A, Donnini S, Granger HJ, Fazzini A, Ledda F (2001) Alpha(1d)-adrenoceptors cause endothelium-dependent vasodilatation in the rat mesenteric vascular bed. J Pharmacol Exp Ther 296:869-875

Graham RM, Perez DM, Hwa J, Piascik MT (1996) Alpha 1adrenergic receptor subtypes. Molecular structure, function, and signaling. Circ Res 78:737-749

Heusch G, Baumgart D, Camici P, Chilian W, Gregorini L, Hess O, Indolfi C, Rimoldi O (2000) Alpha-adrenergic coronary vasoconstriction and myocardial ischemia in humans. Circulation 101:689-694

Hodges RR, Shatos MA, Tarko RS, Vrouvlianis J, Gu J, Dartt DA (2005) Nitric oxide and cgmp mediate alphald-adrenergic receptorstimulated protein secretion and $\mathrm{p} 42 / \mathrm{p} 44$ mapk activation in rat lacrimal gland. Invest Ophthalmol Vis Sci 46:2781-2789

Huang Y, Wright CD, Merkwan CL, Baye NL, Liang Q, Simpson PC, O'Connell TD (2007) An alpha1a-adrenergic-extracellular signal-regulated kinase survival signaling pathway in cardiac myocytes. Circulation 115:763-772

Jensen BC, Swigart PM, De Marco T, Hoopes C, Simpson PC (2009a) \{alpha\}1-adrenergic receptor subtypes in nonfailing and failing human myocardium. Circ Heart Fail 2:654-663
Jensen BC, Swigart PM, Laden ME, DeMarco T, Hoopes C, Simpson PC (2009b) The alpha-1d is the predominant alpha-1-adrenergic receptor subtype in human epicardial coronary arteries. J Am Coll Cardiol 54:1137-1145

Jensen BC, Swigart PM, Simpson PC (2009c) Ten commercial antibodies for alpha-1-adrenergic receptor subtypes are nonspecific. Naunyn-Schmiedebergs Arch Pharmacol 379:409412

Jones CJ, DeFily DV, Patterson JL, Chilian WM (1993) Endotheliumdependent relaxation competes with alpha 1- and alpha 2-adrenergic constriction in the canine epicardial coronary microcirculation. Circulation 87:1264-1274

Kojima Y, Sasaki S, Oda N, Koshimizu TA, Hayashi Y, Kiniwa M, Tsujimoto G, Kohri K (2009) Prostate growth inhibition by subtype-selective alpha(1)-adrenoceptor antagonist naftopidil in benign prostatic hyperplasia. Prostate 69:1521-1528

Lian J, Marcinkiewicz C, Niewiarowski S, Beacham DA (2001) Extracellular signal-regulated kinase (erk) activation is required for gp ibalpha-dependent endothelial cell migration. Thromb Haemost 86:1555-1562

Mavria G, Vercoulen Y, Yeo M, Paterson H, Karasarides M, Marais R, Bird D, Marshall CJ (2006) Erk-mapk signaling opposes rhokinase to promote endothelial cell survival and sprouting during angiogenesis. Cancer Cell 9:33-44

Mendez E, Calzada C, Ocharan E, Sierra A, Castillo C, Ramirez I, Meaney E, Meaney A, Asbun J, Miliar A, Herrera J, Ceballos G (2006) Differential expression of alpha1-adrenergic receptor subtypes in coronary microvascular endothelial cells in culture. Eur J Pharmacol 546:127-133

Murohara T, Asahara T, Silver M, Bauters C, Masuda H, Kalka C, Kearney M, Chen D, Symes JF, Fishman MC, Huang PL, Isner JM (1998) Nitric oxide synthase modulates angiogenesis in response to tissue ischemia. J Clin Invest 101:2567-2578

Nakagami H, Morishita R, Yamamoto K, Taniyama Y, Aoki M, Matsumoto K, Nakamura T, Kaneda Y, Horiuchi M, Ogihara T (2001) Mitogenic and antiapoptotic actions of hepatocyte growth factor through erk, stat3, and akt in endothelial cells. Hypertension 37:581-586

Nishino Y, Masue T, Miwa K, Takahashi Y, Ishihara S, Deguchi T (2006) Comparison of two alpha1-adrenoceptor antagonists, naftopidil and tamsulosin hydrochloride, in the treatment of lower urinary tract symptoms with benign prostatic hyperplasia: a randomized crossover study. BJU Int 97:747-751, discussion 751

O'Connell TD, Ishizaka S, Nakamura A, Swigart PM, Rodrigo MC, Simpson GL, Cotecchia S, Rokosh DG, Grossman W, Foster E, Simpson PC (2003) The ala/c- and alb-adrenergic receptors are required for physiological cardiac hypertrophy in the doubleknockout mouse. J Clin Invest 111:1783-1791

O'Connell TD, Swigart PM, Rodrigo MC, Ishizaka S, Joho S, Turnbull L, Tecott LH, Baker AJ, Foster E, Grossman W, Simpson PC (2006) Alpha1-adrenergic receptors prevent a maladaptive cardiac response to pressure overload. J Clin Invest 116:1005-1015

Pradidarcheep W, Stallen J, Labruyere WT, Dabhoiwala NF, Michel MC, Lamers WH (2009) Lack of specificity of commercially available antisera against muscarinergic and adrenergic receptors. Naunyn-Schmiedebergs Arch Pharmacol 379:397-402

Secchiero P, Gonelli A, Carnevale E, Milani D, Pandolfi A, Zella D, Zauli G (2003) Trail promotes the survival and proliferation of primary human vascular endothelial cells by activating the akt and erk pathways. Circulation 107:2250-2256

Takei R, Ikegaki I, Shibata K, Tsujimoto G, Asano T (1999) Naftopidil, a novel alphal-adrenoceptor antagonist, displays 
selective inhibition of canine prostatic pressure and high affinity binding to cloned human alpha1-adrenoceptors. Jpn J Pharmacol 79:447-454

Turnbull L, McCloskey DT, O'Connell TD, Simpson PC, Baker AJ (2003) Alpha 1-adrenergic receptor responses in alpha 1ab-AR knockout mouse hearts suggest the presence of alpha 1d-ar. Am J Physiol Heart Circ Physiol 284:H1104-H1109
Vinci MC, Bellik L, Filippi S, Ledda F, Parenti A (2007) Trophic effects induced by alpha-1d adrenoceptors on endothelial cells are potentiated by hypoxia. Am J Physiol Heart Circ Physiol

Zembowicz A, Hecker M, Macarthur H, Sessa WC, Vane JR (1991) Nitric oxide and another potent vasodilator are formed from NGhydroxy-L-arginine by cultured endothelial cells. Proc Natl Acad Sci USA 88:11172-11176 